\section{Fracture mechanism of Henbury meteorite by separation along surfaces of shear faulting}

THE smallest Henbury meteorite crater contained ${ }^{1}$ a massive iron that had broken into four pieces weighing 132.7, 54.4, 10.9 and $2.3 \mathrm{~kg}$, respectively. When these four pieces were excavated from the depths of the crater they were found to be still juxtaposed to one another. We have studied a $5 \mathrm{~kg}$, $20 \times 40 \mathrm{~cm}$ slice (BM 1932, 1359) taken from the largest of these pieces. We have also prepared and studied sections cut from a number of pieces of 'shrapnel' from a Henbury crater, weighing about $100 \mathrm{~g}$ and purchased from the American Meteorite Laboratory.

The macrosection BM 1932, 1359 is traversed by a number of fault displacements, most of which are continuous across the whole section and lie approximately parallel to an outer edge of the section. This suggests that, in this instance, the fracture surfaces could represent the extreme situation in which limited shear displacement gives way to physical separation along the fault surface. This macrosection is too large for satisfactory microscopic examination, and, consequently, the fracture mechanism was explored using the smaller shrapnel fragments. In each instance slip-fault displacements were encountered within the shrapnel pieces, and in one instance an internal crack was found to merge continuously into a pronounced displacement fault. The most convincing evidence for fracture by separation along the surfaces of shear faults, however, comes from those pieces of shrapnel that were not reheated significantly during break-up. In those cases, the bulk of the kamacite $(\alpha \mathrm{Fe}-\mathrm{Ni})$ is shock hardened but not recrystallised. Shear-displacement surfaces within these specimens were revealed (by Nital etch) as continuous traces of fine grained $(1-5 \mu \mathrm{m})$ recrystallisation in the kamacite, similar to geological mylonitisation zones. The 'throw' of the fault varies from a few micrometres to several millimetres and is best seen where particles of taenite $(\gamma \mathrm{Fe}-\mathrm{Ni})$ are cut and displaced. The Nital etch did not reveal recrystallisation in the taenite and, consequently, the metallographically visible 'thickness' of the shear effect in taenite was limited to the apparently sharp geometrical surface of displacement. But the heat that is generated during the rapid propagation of the displacement fault causes the shock-hardened kamacite to recrystallise within a zone of finite thickness on either side of the surface of displacement. The visible width of this recrystallised zone varies from 1 to $20 \mu \mathrm{m}$ according to the energy input at the particular fault.

We have examined a number of sections of Henbury 'shrapnel' in which relics of this 'mylonitised' kamacite are present at the outer fracture surfaces. To identify these relics of heat effect with shear mylonitisation, it is necessary to eliminate the possibility that the surface heating was produced by ablative friction during high-velocity flight through the atmosphere ${ }^{2}$. It is possible to do this since an ablative heat alteration zone ${ }^{3}$ is composed of coarse ragged $\alpha_{2}$ (martensitic) product that indicates reheating above $850{ }^{\circ} \mathrm{C}$, whereas, by contrast, the effect observed at the surface of Henbury shrapnel is a fine-grained, recrystallised $\alpha$ (non-martensitic): the product of a much milder heating of shock-hardened kamacite.

The presence of shocked kamacite in Henbury shrapnel indicates that the fragmentation took place under conditions of shock loading with a shock pressure of at least $130 \mathrm{kbar}$. The shear faults seem to be superimposed upon the shockhardened structure and, therefore, seem to have formed subsequently.

Once the fault has commenced to move on a selected surface it is likely to continue to do so because of the local generation of heat and the superplastic lubrication of the small kamacite grains in the mylonitised zone. The factors that cause a particular surface to be selected for shear faulting are, however, more difficult to specify, but, in general terms, they must arise from unbalanced shear forces as the projectile adjusts itself rapidly to the complex array of shock waves that accompany high-velocity impact with the Earth.

We thank the authorities of the British Museum (Natural History) for the preparation and loan of the specimen BM 1932, 1359.

H. J. AxON

E. M. STEEle-Perkins

Metallurgy Department,

The University,

Manchester M13 9PL, UK

Received June 16; accepted July 9, 1975.

Spencer, J. L., Min. Mag., 23, 387 (1933).

Nininger, H. H., Ward's nat. Sci. Bull., 24, 21 (1950).

Brentnall, W. D., and Axon, H. J., J. Iron Steel Inst., 200, 947 (1962).

\section{Mechanism of the oxidation of ethylene by palladium(II)}

THE oxidation of ethylene to acetaldehyde by aqueous palladium chloride forms the basis of the Wacker process. The kinetics and mechanism of this reaction have been extensively studied for ethylene and other olefins, and most authors assume that the formation of a cis hydroxoethylenepalladium complex is an essential step in the reaction ${ }^{1-4}$. We propose here a new mechanism by which the trans intermediate, $\left[\mathrm{C}_{2} \mathrm{H}_{4} \mathrm{Pd}(\mathrm{OH}) \mathrm{Cl}_{2}\right]^{-}$, may directly yield the palladium $\sigma$-hydroxyalkyl species without the necessity of trans-cis isomerisation or the attachment of a fifth ligand.

It is widely accepted that the first steps of the reaction are the formation of a $\pi$-ethylene complex, $\left[\mathrm{C}_{2} \mathrm{H}_{4} \mathrm{PdCl}_{3}\right]^{-}$(Fig. 1a) the palladium analogue of Zeise's salt, followed by the aquation and dissociation of the trans aquo complex to give trans $\left[\mathrm{C}_{2} \mathrm{H}_{4} \mathrm{Pd}(\mathrm{OH}) \mathrm{Cl}_{2}\right]^{-}$(Fig. 1 b). A trans to cis isomerisation is then assumed with the subsequent insertion of the ethylene into the palladium-hydroxide bond (a cis-migration rearrangement) giving a palladium $\sigma$-hydroxyalkyl molecule $\left[\mathrm{PdCl}_{2} \mathrm{CH}_{2} \mathrm{CH}_{2} \mathrm{CH}_{2} \mathrm{OH}\right]^{-}$(Fig. 1c) which yields acetaldehyde by a palladium assisted hydride shift. Little attention ${ }^{5,6}$ has been focused on the isomerisation of $\left[\mathrm{C}_{2} \mathrm{H}_{4} \mathrm{Pd}(\mathrm{OH}) \mathrm{Cl}_{2}\right]^{-}$ although it has been suggested ${ }^{1,7}$ that a dihydroxo species is involved as an intermediate. An alternative view ${ }^{4,8,9}$ is that a five-coordinate palladium(II) species is involved, thus avoiding the requirement of the cis configuration. The kinetic evidence for these latter proposals has been obtained at low chloride and acid concentrations and is somewhat unconvincing in the normal concentration range so that the isomerisation of $\left[\mathrm{C}_{2} \mathrm{H}_{4} \mathrm{Pd}(\mathrm{OH}) \mathrm{Cl}_{2}\right]^{-}$remains controversial.

We have already suggested ${ }^{10}$ a model for catalysis by nickel (II) complexes, which was based upon the facilitation of certain molecular vibrations by the vibronic coupling of the highest filled molecular orbital with vacant molecular orbitals derived

Fig. 1 Compounds occurring during the oxidation of ethylene by palladium(II): $a$, $\pi$-ethylene complex; $b, \operatorname{trans}\left[\mathrm{C}_{2} \mathrm{H}_{4} \mathrm{Pd}(\mathrm{OH})\right.$ $\left.\mathrm{Cl}_{2}\right]^{-} ; c$, the palladium $\sigma$-hydroxyalkyl molecule $\left[\mathrm{PdCl}_{2} \mathrm{CH}_{2} \mathrm{CH}_{2} \mathrm{OH}\right]^{-}$.

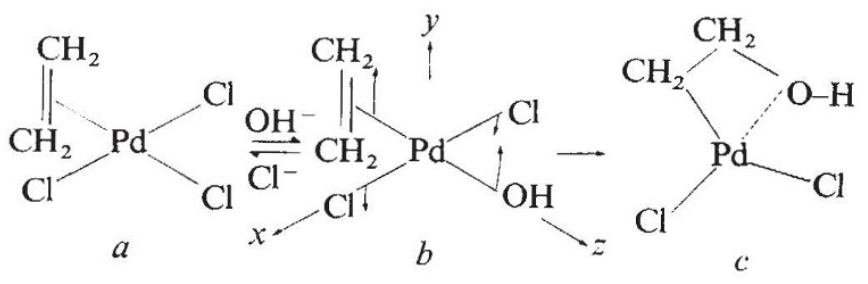

